\title{
FUNCTIONAL ENHANCEMENTS TO PROJECT MANAGEMENT INFORMATION SYSTEMS
}

\author{
Jacek MOSZKIEWICZ*, Katarzyna ROSTEK** \\ *GE Company Polska Engineering Design Center, Warsaw, Poland \\ jacemos@gmail.com \\ **Faculty of Management \\ Warsaw University of Technology, Warsaw, Poland \\ k.rostek@wz.pw.edu.pl
}

\begin{abstract}
Presented research work relates to information systems of projects management support. The aim of the work is to propose solutions, that will help achieve improved efficiency of information systems class PMIS implementations (Project Management Information System) especially given the scope of functionalities and implementation process realization. Presented in this article research results were obtained in the analysis of projects implemented in enterprises of the sector: construction and building, service with particular emphasis on the IT industry, and investment. Summary of the article includes both the results of the research analysis and proposed directions for their further development.
\end{abstract}

Key words: the project, the project portfolio, project management information system, project management body of knowledge, project life cycle, the cycle of implementation and monitoring of the project.

\section{1}

\section{Introduction}

Project management is a relatively new field of knowledge $^{1}$, if we accept the first works describing the methodology ${ }^{2}$ of project management as its beginning. A project is a venture which aims to build an office building, drafting a law, producing an atomic bomb or software. The fact is that ventures, today referred to as projects ${ }^{3}$ by methodologies, were carried out practically since the beginning of humanity. The fact that projects have been carried out for centuries without the support provided by methodologies today, often makes the field of project management undervalued in companies that base their business on projects.

Similarly, very often a company is not willing to invest funds in implementing a methodical, standardized project management approach. If business operations pro-

\footnotetext{
${ }^{1}$ The origins of project management as a field of knowledge date back to the beginning of the 50 s of the twentieth century. [information after Webb A. - Earned Value in Practice. Warsaw, PROED 2008]

${ }^{2}$ Methodology - a set of rules regarding a manner of execution of certain work. [Polish Language Dictionary PWN, http://sjp.pwn.pl/slownik/2567700/metodyka (read on 29 May 2011)].

${ }^{3}$ Project - a unique sequence of complex tasks, related to one another, having a common goal, intended for delivery, within a specified time, without exceeding the budget, according to set requirements [definition after Wysocki R.K., McGary R. - Effective Project Management. Edition III. Gliwice, Helion 2005, p. 47].
}

duce desired results at the level of whole organization, often no attention is paid to the possibility of improving the conduct of individual projects, or even to their failures. This issue is particularly relevant for Polish companies, which often in contrast to some of their Western and American counterparts, have not yet developed a culture of project management. However, this does not mean that corporations in highly-developed countries cope flawlessly with the management of unique projects.

Lack of implemented project management culture is one of the main reasons why the implementation of information systems supports project management (hereinafter referred to as the PMIS $^{4}$ class systems) are ineffective. An ineffective implementation is defined as one which although completed according to schedule and complete, did not result in a continuous and efficient use of PMIS in the organization.

One of the main reasons for the failure of implementation of these systems, which will be considered in this study, is the limitations of their functionality. Lack of functionalities tailored to the needs of individual industries, the lack of functionality tailored to the conditions of the market (Polish or other European markets), little flexibility in system configuration, or even a system poorly matched to the needs of a client, result

4 PMIS - acc. to PMBOK (Project Management Body of Knowledge) standard proposed by Project Management Institute, is a Project Management Information System. 
in the fact despite the efforts of the implementation team and employees, usefulness of the system may not be sufficient. Usefulness is understood as obtaining business benefits through a regular use of PMIS. The above described issues, identified in the course of professional practice, are motivators to undertake a project to improve the efficiency of PMIS implementation.

The aim of this study is to propose solutions that will help achieve improved efficiency of information systems implementation. Due to issues identified during the implementation of these systems, which are described in the introduction to the study, the focus was put on two areas where improvements are achievable:

- functional area of PMIS,

- methodical area of PMIS implementation conduct.

In order to achieve improvement in the first of these areas, the role of a project management support system will be defined, or the rationale for implementing such a system in a company. Then an analysis will be conducted of requirements relating to the functionality of these systems. This analysis aims to answer the following questions:

- What specific objectives should PMIS deliver within methodological project management?

- What specific objectives should PMIS deliver within practical needs reported by business implementation owners?

- What organizations can benefit from the use of such systems?

In the next step, methodological requirements and those derived from business owners originating from different industries, will be juxtaposed with the capabilities of selected PMIS. This set will identify the best systems in the various areas of project management to clients in various industries. In addition, knowledge about the most important requirements relating to the project management processes and definition of a set of existing functionalities, will enable to specify the functionality unique to the market. The aim of the study is therefore to summarize and compare the capabilities of existing solutions and to identify solutions that can improve IT support of project management.

This paper concerns the information systems supporting project management. Due to the fact that the concept of a project exists in many industries, it is very general. A project in each of the industries may mean a sequence of actions with a completely different specificity, which, however, due to their nature and the environment in which they are implemented, will be combined by one definition.

As a result, it is possible to distinguish techniques and methods of project management, which can be used in almost every industry, such as critical path method or the earned value method. However, there are a number of requirements of individual industries, for which specific solutions are needed to facilitate the planning, implementation and monitoring of projects.

Techniques and methods as a tool for those requirements, translated into the language of a computer system, can be identified with a functional scope that a given system provides to the user.

It was assumed that this study should not only be based on general functionalities that can be used in the majority of industries present on the market and dealing with the implementation of projects. Such a proposal is a result of experience gained in implementation of PMIS. Most clients look for a dedicated solution that is prepared to support the issues and take the challenges which are commonplace for the industry. This is due, in large part, to strong competition on the market, which provokes a practice of creating optimistic schedules and squeezing costs in order to place attractive offers in order to win tenders. It is this dynamic environment of project implementation which results in the fact that companies often do not have time for longterm, multi-phased implementations and, as a result, functionalities are adapted to the needs of a particular industry.

Adjustment works are inevitable, but the client's goal is to reduce them to a minimum. In conclusion, we need tailor-made solutions, and adjustment works, ideally, should be limited only to the specificity of an organization, not the industry.

Results of this approach are already evident at the stage of PMIS license sales. This process is often accompanied by a preliminary stage of analysis of client's requirements regarding project management, so as to avoid a situation in which during the implementation works, it appears that a wrong system was matched. Software vendors also notice a search for more precisely dedicated solutions, who in some cases, decide to restrict the functionality of the system to a particular industry at the expense of other possibilities. 
One of the purposes of this study, described in the previous subsection, is the possibility of its practical application and translating its results into further implementation of PMIS. Therefore it was decided to make a clear separation of the described requirements and functionalities of information systems between industries on the market. The time frame allocated to this work, however, does not allow to take such a broad scope that it was possible to describe specific requirements of all of the industries on the market. A choice was made, therefore, to select these types of projects whose specific requirements seem to diverge most from each other, yet they represent requirements of several similar industries or a market sector:

- construction designs (marked on a spreadsheet as Constr.),

- services sector projects, with particular emphasis on the IT sector (marked on a spreadsheet as IT),

- investment industry projects i.e. investors active on the construction and energy markets, and other investors financing and ordering the execution of projects to subcontractors.

2

\section{The Role of PMIS in a company}

This chapter aims to answer the following questions:

- what is PMIS?

- what caused the need to use such systems?

- why are PMIS used?

- what types of PMIS are present on the market and when should an organization consider using a particular type of system?

This chapter provides an introduction to a detailed analysis of market requirements and as such will be maintained at a high level of generality. This means that there will be presented main objectives of the use of this type of IT systems and the direction of further consideration.

\subsection{Definition of PMIS}

"Project Management Information System [Tool] a system consisting of tools and techniques used to collect, merge and transfer results of project management processes. Used as support for all aspects of a project from its beginning to the end. Could comprise both manual and automatic systems. ${ }^{5}$

This definition outlines the key functionalities of PMIS. To paraphrase, these systems are a collection of IT tools that allow the use of project management techniques for delivery of process throughout the life cycle of a project. ${ }^{6}$

This definition, although very general, covers the entire functional scope of these systems. It will not be, deliberately, developed in this subchapter, as further elements of the definition are closely related to the types PMIS described later in this article.

\subsection{The purpose of using PMIS}

Over the past hundred years, many organizations have developed their own methodologies for managing projects, often without using the nomenclature characteristic of modern project management methodologies and this study.

These organizations have developed their own systems of work, which allow effective implementations, peculiar to their industry and business ventures. Such knowledge of the organization is often referred to today as "know-how." This "know-how" was retained in organizations in various forms.

Most commonly it was the knowledge of individuals, personally handed over to further employees. More preventive organizations took care to preserve the knowledge in the form of paper documentation (notebooks, binders, punch card system). Along with technological advancement there is a gradual computerization of companies. It results in saving a number of project data in electronic form and the introduction of successive file formats specific to the data contained in them.

The advantage of project management information systems in supporting project management over their predecessors is in the assumption of the possibility

\footnotetext{
${ }^{5}$ Project Management Institute - PMBOK Guide - Fourth Edition. Warsaw, Management Training \& Development Center 2009, p. 470.

6 Project life cycle - a division of project into phases in managerial terms. There are usually four to five phases, depending on the methodology. This may be Initiating, Planning, Implementation and Control, Completion as in the case of PMBOK, or Identifying and organizing, Planning, Performance management and Completion as suggested by Harvard Business Essentials in "Managing large and small projects".
} 
of storing all the necessary project data in a central database. This approach, adequately protected from the hardware, software and procedures point aspect, supports the implementation of the following functions:

- knowledge preservation,

- data recording standardization,

- data confidentiality (management of access privileges),

- data integrity (documentation is adequate, complete and up-to-date),

- data availability (data is available upon request),

- facilitated data search,

- ensured data sustainability (assuming maintenance of hardware and software).

To sum up, these systems are used, among others, to organize knowledge about project management in the organization.

In the definition presented in the previous subchapter another basic function of PMIS was quoted, which is appropriate project management support. The IT system, through close links between functionalities supporting various project management processes, can force a user to a sequence of activities consistent with the methodology. A methodical action improves the efficiency of running a project. An example would be a situation when a user, such as a project manager, needs to file a report about the progress of the project with their supervisor. Using an IT system the report can be formatted and generated within a few seconds/ minutes. A condition is, however, appropriate planning of the project according to the needs (detailed project structure, resources, expenses, etc.) in the initial phase of the project, and then providing regular updates on progress of works. In a situation where PMIS is not used, drawing an appropriate report may take up to several hours. During the manual preparation one should reckon with the errors of human nature.

During training and implementation of PMIS one can meet with the opinion (of the more ambitious users) that a properly formatted spreadsheet can be used for carrying out projects. Certainly, running a small project (let's assume a dozens of actions) in this way is possible, however, the lack of predefined functionalities dedicated to the implementation of project management processes makes it difficult. Especially in the course of large projects (a major project is defined as a project consisting of some 500 activities and more, lasting approximately one calendar year and longer), it becomes a very laborious task. This chapter is not intended to define requirements, but it is worth quoting one of the most fundamental thesis to confirm the need for dedicated solutions to support project management. A project schedule changes several times during each phase of the project life cycle, the initial revisions during initialization, subsequent ones during the planning and implementation and a vast majority during regular update of the project and change management. A person executing a schedule update process should have a tool, which on the basis of changes in the duration of at least one action would automatically calculate changes for all activities in the schedule. Otherwise, the updates can be lengthy and involve a number of errors. These errors, in turn, can lead to delays that often result in serious consequences for the project and those responsible for its results.

Another advantage of using a PIMS is the ability to analyze multiple perspectives of the same data, e.g. grouping of project activities through various criteria and a summarizing data according to a specified criteria. The ability to analyze multiple perspectives does not apply to actions only, but also to more detailed data such as resources or costs attributable at their level.

A PMIS is particularly useful when the organization is dispersed among several locations. In this situation, a central database with a standardized method of entering data helps to provide timely information whenever and wherever it is needed. Another advantage is that data is available at each location, immediately after its entry. Other main objectives of using PMIS will be described, depending on the type of system chosen by an organization.

\subsection{Classification of PMIS}

The following classification does not come directly from any of the methodologies, however, is a result of combining the experience in applying PMIS with the nomenclature adopted by their manufacturers.

\section{- EPPM}

EPPM - Enterprise Portfolio Project Management is a system that is based on a central database, shared on a network and enabling data sharing between projects stored in it. An important feature of the system is the ability to analyze data about projects at the level of individual projects and project groups, known 
as programs $^{7}$ or project portfolios ${ }^{8}$. Frequently, these systems have built-in functionalities for conducting portfolio analysis, whose aim is selection.

They are the type of enterprise systems, which are based on the Client-Server architecture, the application is installed on a single machine, which refers to a database working on a server. Most often such a system also has the possibility of access to projects through a browser.

Rationale for the use of a EPPM system:

- many users of the system,

- different levels of access for individual users,

- resource management shared between projects,

- a need for portfolio analysis,

- management is scattered in different locations, departments or even different floors of a large corporate building,

- a need to edit data by multiple users simultaneously.

\section{- PPM}

PPM - Project Portfolio Management is a system that can be based on a database, but equally well project data can be stored in files. This follows from the fact that it does not provide data on the network. An important feature of the system, as in the case of EPPM, is the ability to analyze data about projects at the level of individual projects, programs and project portfolios.

Most of these systems do not have the functionality used to conduct portfolio analysis. These are standalone systems, or based on the Client-Server architecture, the application installed on a single machine, which refers to the local database/file system.

\footnotetext{
${ }^{7}$ The program - the program is a set of projects. Projects in the program must be implemented in a specific order, which is a condition for completion of the program. [Wysocki R.K., McGary R. - Efektywne Zarzqdzanie Projektami. Wydanie III. Helion, Gliwice 2005]. The program implements a number of objectives, centered around the main business purpose such as NASA's space program, a program for building industrialtechnological park, the program of preparations for Euro 2012 (author's note).

${ }^{8}$ The project portfolio - the project collection that are closely interconnected [Wysocki R.K., McGary R. - Efektywne Zarzadzanie Projektami. Wydanie III. Helion, Gliwice 2005]. This definition indicates that the concept of portfolio is wider than the concept of program. Therefore, the program is a special case of the portfolio, and the portfolio may also contain more than one program (author's note).
}

Rationale for the use of a PPM system:

- one or a maximum of a few users with a license leased for the time of work with the system (concurrent),

- no need to distinguish between the privileges of users,

- projects are conducted by independent resources,

- a need to summarize data on many projects, but no advanced portfolio techniques are used,

- users usually use the system in one location and do not need remote access.

\section{- PM}

PM - Project Management is a system very similar to the described above PPM, but it does not have the ability to summarize data on many projects. In practice, this means that it work on individual, independent files, or storing a number of projects in a database is not able to aggregate data derived from them. Such systems can be divided into two main types:

- legacy systems that do not take into account the possibility of working in a network (often freeware),

- systems dedicated mainly to the construction, design, and energy industries, which are not intended to handle projects independently of each other in terms of the budget, resources, location, and business objectives.

Rationale for the use of PM systems:

- carrying out projects that have exclusive resources, their own budget, whose implementation is independent of other projects of the organization, such as, an office building construction, a part of a motorway, a bridge),

- other points of rationale similar to a PPM system.

\section{- LPM}

LPM - Linear Project Management is a special case of PM, a dedicated system for managing linear building and construction projects. Linear projects are all these projects, whose implementation takes place in a large space, often associated with many sq.km. Such projects are building roads, bridges, subways, railways. An important factor that determines the diversity of such projects from others is the use of appropriate resources not only at the right time, but also the right place. 
Hence, the LPM systems are characterized by an additional variable affecting the shape of the schedule and resource estimate, which is the distance at which work is carried out.

\section{- PRM}

PRM - Project Risk Management is a system primarily dedicated to project risk management. PRM software is functionally designed to handle primarily one area of project management, and therefore its characteristics differ from other types of systems described in the classification. For this reason, PRM systems will not be the main theme of the study, and during a functional review of PMIS only one representative of PRM will be mentioned. However, risk management is an extremely important area of project management, therefore we have decided to include this type of system in the list.

\section{Rationale for the use of PRM systems:}

- running projects with a high level of uncertainty of time, resources, and costs,

- running projects related to the probability of occurrence of events affecting the project, both positive and negative,

- running projects whose implementation is affected by weather conditions,

- running projects whose products are characterized by a low degree of repeatability.

Other points of rationale similar to PPM systems.

\section{Analysis of users' functional requirements}

An analysis of functional requirements for PMIS will be made based on requirements articulated by clients in the process of obtaining contract, training, and implementation and analytical work ${ }^{9}$, derived from delivery of own projects ${ }^{10}$ and defined on the basis of project management methodology.

In section 3.1 List of PMIS implementations there is a brief description of implementation, training and projects that are the source of requirements of individual industries.

\footnotetext{
${ }^{9}$ Training and implementation work on IT projects supporting project management, project documentation, and project risk.

${ }^{10}$ Web application software projects, conceptual design for the architecture for data exchange.
}

The analysis will be based on the main axis of distribution of project management processes in PMBOK, or on groups of processes reflecting the life cycle of a project. Subsequently, the requirements that will be defined, will be ordered according to their affiliation to the process, implemented under a project life cycle phase. The processes will be presented in terms of the scope of information and activities necessary for their implementation and functional requirements that result from this scope for IT systems. For those of the functional requirements that are derived from specific industries a source of a given requirement will be indicated to an accuracy of one of the organizations listed in section List PMIS implementations and the role in the company, whose owner reported a requirement. This will make it possible to determine the weight of specific requirements for individual industries. Requirements defined in this way will be described using metadata in the following manner:

metadata $=[$ No., requirement, processes group, process, scope, requirement source, weight]

where:

- functionality area of PMIS,

- methodical area of the implementation of PMIS,

- No. - ordinal number,

- requirement - a brief description of the currently described requiremen,

- processes group - one of the five major groups of processes involved in a project life cycle,

- process - one of the activities that make up a processes group,

- area - one of nine areas of project management,

- scope - indication on the part of the process that generates a given requirement,

- weight - subjective assessment of the weight of a requirements for the utility of a system, divided into three main industries:

- constr. - construction and building industry,

- IT - information/services industry,

- inv. - investment industry.

It was assumed that the weight is necessary for the valuation of the functionality to allow for effective evaluation of the solution.

- source of requirement,

- industry - information defining the source of requirement,

- role - position of the employee in the organization who defined the requirement. 
Metadata were used to create a table comparing the systems. The Weight field has a direct impact on the results of the comparison. Based on the structure generated during the analysis, a comparison of functionality of selected PMIS was conducted with a breakdown into industries.

\subsection{A list PMIS implementations}

This section outlines the business and characteristics of enterprises in which carried out implementations or individual stages of implementations, constitute a source of users' requirements for this study.

Professional ethics in the work of a consultant obliges to maintain secrecy in relation to the processes that occur on the client's side and how they are implemented. Therefore, instead of company names contractual ID will be given and business details will be replaced by general characteristics.

Construction and building industry (construction, metal construction, energy):

- company R - an enterprise engaged in construction and support of operation of mines in South America; the main requirement area is risk management,

- company X - a factory delivering metal constructions designs, the challenge was the central database of designs and schedule management,

- company $\mathrm{Y}$ - a factory delivering metal constructions designs, the challenge was the central database of designs and resource management,

- company K - a construction company focused on building roads and bridges, the important issue was performance management and location of equipment,

- company W - construction general contractor, the main requirement was the management of documentation and schedule,

- company S - a construction company focused on road construction, work mainly focused on estimating costs and registering their level at different levels of acceptance,

- company $\mathrm{P}$ - a construction company, focused on rental of formwork, the primary requirement was to calculate available formworks and their consumption depending on the type of project,
- company L - contract management; the main requirements related to document management and recording of communication within the project,

- company O - an enterprise engaged in designing and manufacturing metal structures (EngineeringProcurement-Construction) implementing projects for the oil sector; requirements related to the majority of solutions described in this study, except the management of stakeholders, documentation and costs.

Investment industry:

- company Z - a construction investor, in the opinion of users, the system was mainly used to control a project development from the management's point of view,

- company I - an energy sector investor, looking primarily for advanced tools of financial analysis and risk management.

Service Industry (IT, services):

- company A (Services - marketing and sales) a representative of a well-known pharmaceuticals manufacturer, developing schedules and work sheets reporting,

- company B (IT - software development) - a budget unit implementing, among others, IT projects; primarily focused on managing schedules and cost, communication within the team, reporting through data tables,

- company C (IT - software development) - an insurance agency, IT department, portfolio management, long-term resource plan development.

- company D (IT-hardware) - a subsidiary of a corporation responsible for designing and selling equipment on the IT market, schedule management and analysis of resource load,

- enterprise E (IT - software development) a manufacturer of computer games, synchronization of schedules,

- company F (IT - software development) a manufacturer of electronic components and drivers for the automotive industry; project plans to manage a team of designers, subcontractors, provide performance qualitative metrics and synchronize design schedules with production ones,

- company H (IT - software development) - a large publishing house, interested in risk management, documentation and improvement of communication in making business decisions, 
- company J (IT Consultants - software implementation) - a company running implementations, consulting and training in information systems; building schedules, reporting consultants' work, automatic updates, analysis of loads by hours paid by the client and own,

- own work:

- Computer Networks - a dynamic web site based on Content Management System (php, mysql, ajax),

- Designing an Infrastructure for Scientific Communication - a project to unify the data format (theoretical part),

- Editor's Choice - a dynamic web site (python, mysql).

\subsection{Determination of requirements, review of existing solutions and proposal of new ones}

During the research were examined 30 processes in 9 areas of project management and across the entire project management cycle to determine 64 user and methodical requirements. The requirements are described based on the practical application of PMIS in enterprises. As a result, not only have the requirements of project-oriented planning and preservation of knowledge after its implementation been considered, but also those associated with implementation of processes groups, monitoring and control. It is the up-to-date progress reporting and change management in a project that may affect the majority of its dimensions which is one of the biggest challenges in the effective use of PMIS in the organization.

Fig. 1 has outlined, at an overall level, an implementation and control cycle of a project using a PMIS, which takes into account the use of work cards. The described cycle can form the basis for making one of several major project management procedures in an organization, and should particular steps should be described with detailed user instructions. These instructions would be created on the basis of the functionalities of the system chosen by the organization.

In response to these and all other requirements there have been defined 220 functional solutions, of which 63 are called innovative solutions. These are unprecedented solution for the tested systems.

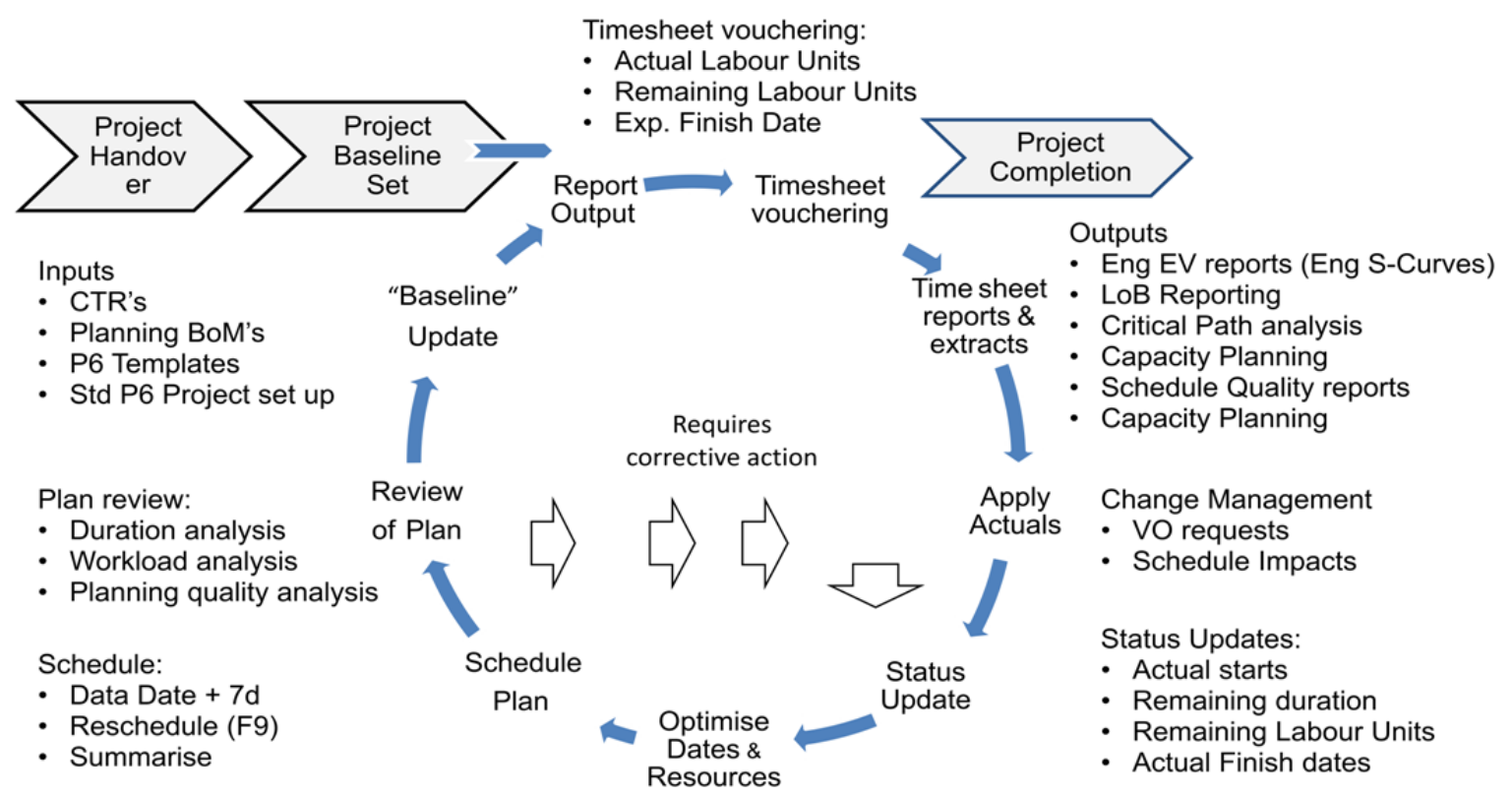

Figure 1. The cycle of implementation and monitoring of the project using a PMIS (source: own work based on ${ }^{I I}$ )

\footnotetext{
${ }^{11}$ Project Management Institute - Project Management Body Of Knowledge Guide - Fourth Edition. Management Training \& Development Center, Warszawa 2009.
} 
Limitations associated with the MA thesis framework did not allow comparison of all major systems PMIS on the market. There lacked functional combines i.e. CA Clarity and IBM Rationale, solutions available only through a browser such as @ task or Blue Ant and the open source type of solutions with strongly reduced functionality as dotProject and Gantt Project.

However, the tools supplied in Excel spreadsheets allow appropriate extension of the comparison, so that it also included the evaluation of competitive solutions against those presented ones. Systems have been selected mainly on the basis of experience gained in working with them, that is no system testing was involved, whose functional scope was not known. Another selection criterion was to show a range of solutions available on the market, which will show the advantages and disadvantages of different types of PMIS mentioned in chapter four (EPPM, PPM, PM, LPM, RPM).

Eventually, systems selected for comparison are:

- Primavera P6 v 7.0, hereinafter referred to as Primavera P6 and P6,

- MS Project 2010, hereinafter referred to as MS Project,

- ASTA PowerProject v 11.0, hereinafter referred to as Asta Powerproject or Asta,

- Pertmaster (Primavera Risk Analysis) v 8.7, hereinafter referred to as Pertmaster (PRA),

- TILOS v7.0, hereinafter referred to Tilos or TILOS.

Below is a summary of the proposed functional solutions. This summary is intended to provide areas for improvement and problems which the 63 solutions presented in detail in the article are supposed to address:

- Information management through project organizational structure:

- all communications-oriented functions of the system are powered by the organizational structure combined with a database of users and resources, such as project workflow, issues reporting forms, risk response plan, task distribution lists,

- supplementing the lack of sufficient authority granulation for the management of the lowest, most detailed part of the schedule which is an action; there would be advisable a level of access to an independent determination of the access/control of the duration, resources, ex- penses, labels, and individual user-defined fields,

- storing a complete distribution list of users and resources not being users of the system associated with the project; a table of data would contain information such as e-mail addresses, contact details, preferred channels of communication, frequency of report delivery, broken down into pre-defined categories derived from the organizational structure of the project (project sponsor, managers of the project, primary user, etc.), taking into account their specialization (roles, authority) assigned to each resource (designer, analyst, programmer, etc.).

- Documentation management:

- defined level of control - access to a document can be controlled:

- in relation to the project,

- in relation to users,

- extended range of authority - access to a document for each level of control is implemented in terms of:

- document,

- metadata,

- authority,

- limitation of document formats,

- advanced search after any given parameter among all the metadata and text (with the possibility to exclude any part of them),

- mass document upload,

- adjusting the auto-numbering.

- Project initiation workflow administration:

- workflow templates based on the type of project - the majority of companies specializes in performing various types of projects, such as:

- the construction and design industry,

- IT Industry,

- investment,

For each type one can imagine different rules for initiating and planning, therefore reflecting procedures could be included in a project management tool which would spare the time of employees and ensured implementation consistent with best practices of the organization.

- stages of the workflow in the decision tree system,

- building the workflow depending on the stage of the project, 
- history and transparency of the process:

- ability to track workflow progress by all involved actors in the system, regardless of its stage,

- ability to track all the decisions regarding an individual workflow that the user was invited to, or access to workflow history.

- Project profitability study:

- the fields of financial analysis for the tendering stage - a functionality built into the system of fields and comparative calculation methods would enable the team making an offer to operate much more efficiently,

- parameterized survey to determine the discount rate - incorporating into the mechanism for calculating NPV and ROI, surveys asking questions about selected macro-and micro-economic parameters (current and planned rate of inflation, borrowing rates, the level of investment risk, etc.) would be of great assistance in a proper assessment of the investment,

- NPVR method - that expanded NPV method described for the analysis of profitability of a single project to the level of the portfolio, provides a ratio that allows objective comparison of expected profitability of the undertaken investment,

- investment variation - ability to assign multiple budgeting scenarios and investment development depending on the given criteria.

- Stakeholder management:

- stakeholder register - contains data for the identification of strategies:

- identification data,

- information from evaluation,

- stakeholders classification,

- stakeholders registry authorities - the ability to define authority enabling access to the matrix only to the project manager and the board,

- stakeholders analysis - a proposed tool for stakeholder analysis, which is designed to help in choosing a strategy is a matrix, which compares expected benefits of managing expectations of a given stakeholder with the level of its impact on the project; the duly completed data record results in a stakeholders matrix filled with data and in a strategy for dealing with individual cases, which goes back to the matrix by supplementing it with necessary items.

- Management of base plans:

- a complete baseline plan of performance measurement:

- ensuring that all (at least most) data from plans such as schedule management, resources, costs, risks, and communication interact with each other and affect both the schedule, cost and scope of the project,

- recording all the data from these plans in a baseline plan of performance measurement,

- providing tools that will allow comparison of data from implementation with a defined as a whole project management plan, (data fields, calculations, charts, and fact sheets),

- baseline plan of early/late dates - a functionality that allows for automatic recording of baselines based on the dates:

- the earliest,

- the latest,

- in between the above two,

- creating a baseline risk management plan the ability to create a risk management baseline plan, which would register initial information such as:

- uncertainty estimation,

- risk of events,

- risk register,

- plan for management of each project risk and their impact on the project.

- Requirements and change management:

- hierarchical tree of requirements,

- requirements traceability matrix,

- workflow changes at the level of activities and work packages (Change Order),

- unique identification of data editing - any changes and updates would be stored in the database automatically and stored in the historical form with an accuracy of fields editing, which would provide a close insight into control of management of individual actions,

- integrating the registry of issues with a work plan - ability to determine the impact of a given issue on time and budget of the project,

- integrating the registry of issues with a base plan - implementation of issues whose category/type 
would indicate a change in the scope and would require the user or another person responsible for the introduction of updated baseline plan, which would be a condition for approval of changes (e.g. a change of the status of issues from the category of "Change" to "Closed"),

- workflow integration with the registry of issues workflow retrieves a change order from the Registry of change orders, and returns at least change status such as "approved", or directly affects the parameters of the project,

- workflow templates depend on the type of change - examples of the types:

- change in scope of work,

- change of budget,

- change of dates schedule,

- integrated project change,

- problem,

- request,

- automated control of WBS version,

- automated renumbering when changing the struture.

- Resource management:

- load the resource limits of the project - this feature would be intended to designate the limit load the resource at the project level and, consequently, to calculate the limit of the project with currently available resources,

- automatic updating of the work limit,

- improving the calendar integration - in PMIS there are numerous calendars at different levels of management, such as a system calendar, project calendar, action calendar, resource calendar; the proposed improvement is to create an algorithm for calculating the duration, which will be clear even in complex cases; if not all combinations of calendars can be handled in a logical way, the system should prevent or warn against their use which will significantly facilitate the use of the right combination and will saves a lot of time,

- setting permissions to assign a resource at the project level - assigning authorities to resources:

- at the project level,

- at the level of a single resource,

- at the level of editable labels/codes of resources,
- improved search of qualified resources,

- a summary of long-term planning against the detailed one and their execution - a detailed summary of load charts presenting the level of workhours consumption (for the construction and building industry there should be added the possibility of long-term planning of equipment use) over time, in terms of values planned in the long- and short-term and the actual curve would be a clear and valuable management information.

- Methods of schedule building:

- Critical Chain Project Management (CCPM) proposes improvements in the following areas:

- introduction of resource buffers functionality,

- matrix of buffers use,

- proposing an automating (proposing) mechanism for the transformation of early deadlines schedule into the deadlines schedule,

- proposing a mechanism for resolving resource conflicts,

- advanced multivariate analysis - the curves would present a distribution of duration, costs and man-hours with the possibility to activate their view or exclusion from the analysis, and the calculation and marking on the graph a difference between the displayed variants,

- extensive cost analyst,

- advanced expenditure management,

- managerial reserves management,

- Delphi technique - this functionality would make it possible to assess the duration of individual users with the option of recording their history and comments justifying estimations; the results would be presented in a table, and histogram.

- Risk management:

- the system of authorities for risk management,

- integration of EPPM and RPM.

- Supplier management (a list/register of qualified suppliers):

- separation of resource type for subcontractors,

- combining information about the assignment and subsequent execution of the order with the structure of subcontractors (baseline, subcontractor performance, compliance of performance with objectives), 
- possibility of defining any user fields for the sub-contractors structure.

- Project implementation analysis:

- analysis of the duration reserve:

- indicator of total reserve consumption,

- indicator of total reserve,

- indicator of buffer packet consumption,

- indicator of packet buffer,

- user support - understanding the source of results calculated by using the EV method and their interpretation, poses such difficulties to organizations that even experienced managers are often afraid to use the method,

- analysis of trends in progress (Forecasting) graphical analysis techniques should support recorded in the trends register data on the progress and estimations at various stages of the project,

- comparison of variants of the analyzed variations - at the implementation stage a particularly useful would prove a feature that would allow a clear comparison of results of different calculations used - present used settings in a table, compare them with charts that would illustrate the differences between the curves of the EV method.

- Quality management:

- technical performance record (technical performance measurement) - a register of quality keeping the results of analyses performed using the tools described in the study; the register should allow periodical data collection and their collation in aggregate reports,

- block diagrams - a visual representation of the process, which shows the relationship between the stages, shows the action, their sequence and decision points,

- Run Chart - a chart of performance used for the quality metrics analysis,

- Ishikawa chart (cause and effect),

- Pareto-Lorenz Chart,

- extended schedule evaluation (Project plan quality review) - out of the tested systems, analysis of the logic of the schedule has not been developed to the limit, as shown by Patterson D. [6].
- Reporting:

- work-card team reporting - an improvement, which could increase the use of the solution would be to report work hours by foremen for all their subordinate team,

- reporting using work cards divided into categories of hours - it is important, in terms of the financial settlement of the project, to divide the reported hours into billable/applied) and nonbillable/non-applied; billable hours are those used from the project budget, for which the client pays; the non-billable ones will be paid by the organization from its own budget,

- enhanced methods for graphical reporting a possibility to build curves and other types of graphs described in the study, on the basis of project data, also from the level of userdefined fields,

- tracing users activities (Repository of reports) the possibility to demonstrate the activities of users within different elements of the project; this feature allows to build individual responsibility for activities undertaken within the system,

- a set of closing reports:

- project completion report,

- project evaluation report,

- experience report,

- integration of methodologies database with project database.

\section{Comparison of existing functional solutions of PMIS}

\subsection{Purpose and nature of the comparison}

Objectives of comparison:

- Choosing a system best performing requirements for specific areas of management. The motivation for this kind of comparison is the fact that often organizations, even from the same industries, manage projects in other areas and give up other areas of management. Therefore, a potential reader of this comparison will be able to choose a system that best matches the requirements in their industry, in their areas of interest. In order to be able to perform a constructive comparison of the various areas, certain resource management processes in the area of integration management (long-term planning) and the area of time management (activities resource assessment) has been moved to the area 
of resource management (moved requirements are marked in the Requirements qualification tab by yellow background).

- Selection of the most versatile PMIS, which in the next step will serve as the basis for the development of the missing functional solutions, in relation to competition, and the new proposed ones.

The comparison should be of as objectively as possible. However, total experience of each consultant or user is different and probably largely depends on the nature of the various implementations in which they had the possibility to participate. Taking this into account, it was decided to adapt the form of analysis to user needs, and although the article presents unambiguous results, will allow to assign own industry weights, $\%$ weights of implementation of the process and evaluation of solutions for individual systems, dependent on the experience of individual users. The goal is that anyone interested can take advantage of the tool prepared for this study and be able to adapt he comparison, if they assess a solution differently.

The flexibility of the tool prepared in this way will also be of key importance in the case of testing newer versions of a system, which at the time of writing this article are available for some of the tested ones, such as Primavera P6 v8.0 or Asta Powerproject v12.0.

\subsection{Summary and evaluation of the functionality of selected systems}

Assumptions to make the comparison:

- any functional solution is the answer to a specific requirement assigned to a particular process; both the requirement for a functional solutions and the process in relation to the requirement are linked by a one-to-many relationship,

- each functional solution is evaluated in the scale of 1-10 for each system regardless of the industry,

- each solution meets the functional requirements for the process to a certain extent (percentage), which means that all of the functionalities within a single process add up to $100 \%$,

- the above implies that, regardless of the number of functionalities in the process, each process affects the final general assessment to the same degree (however, not every area will have the same weight as each area may have a different number of separate processes),

- each functional solution receives a final assessment (weighted rating for the sector), resulting from the multiplication of the following values:

- weight for the industry,

- \% share in the process,

- absolute assessment of the functional solutions for a given system,

- points accumulated by individual solutions are aggregated to the level of management areas and to level of the general assessment,

- the results are presented using Tornado graphs which represent each system as a single horizontal bar, where the length of the strip is greater the more points the system received in a given area for a given industry; such presentation allows to compare systems in several dimensions:

- assign places (priorities) to systems based on the number of points scored by them,

- present a difference in the advancement of functional solutions by the difference in the length of the bars (not only 1st and 2nd place, but also a difference between the systems),

- point score on the horizontal scale will illustrate how many and how important solutions were used in different areas - the larger the more important functional solutions,

- additionally, pie charts were used to illustrate the weight that individual systems attach to different areas of project management; the value was calculated based on average points scored by a system in various industries in a given area.

In Fig. 2 in the area of integration management one can see the overwhelming dominance of Primavera P6 v7.0 system over the others.

This is mainly thanks to the rich functionalities provided to the user at the beginning and closure stage of a project as well as the application of great importance to the functionality of issues management, which serves as a registry of change orders.

Nearly as good are MS Project in the IT and Service industry, and the investment one, where a greater importance, than in the construction and building industry, is placed on mechanisms of the workflow type, which are plentiful in the system. 


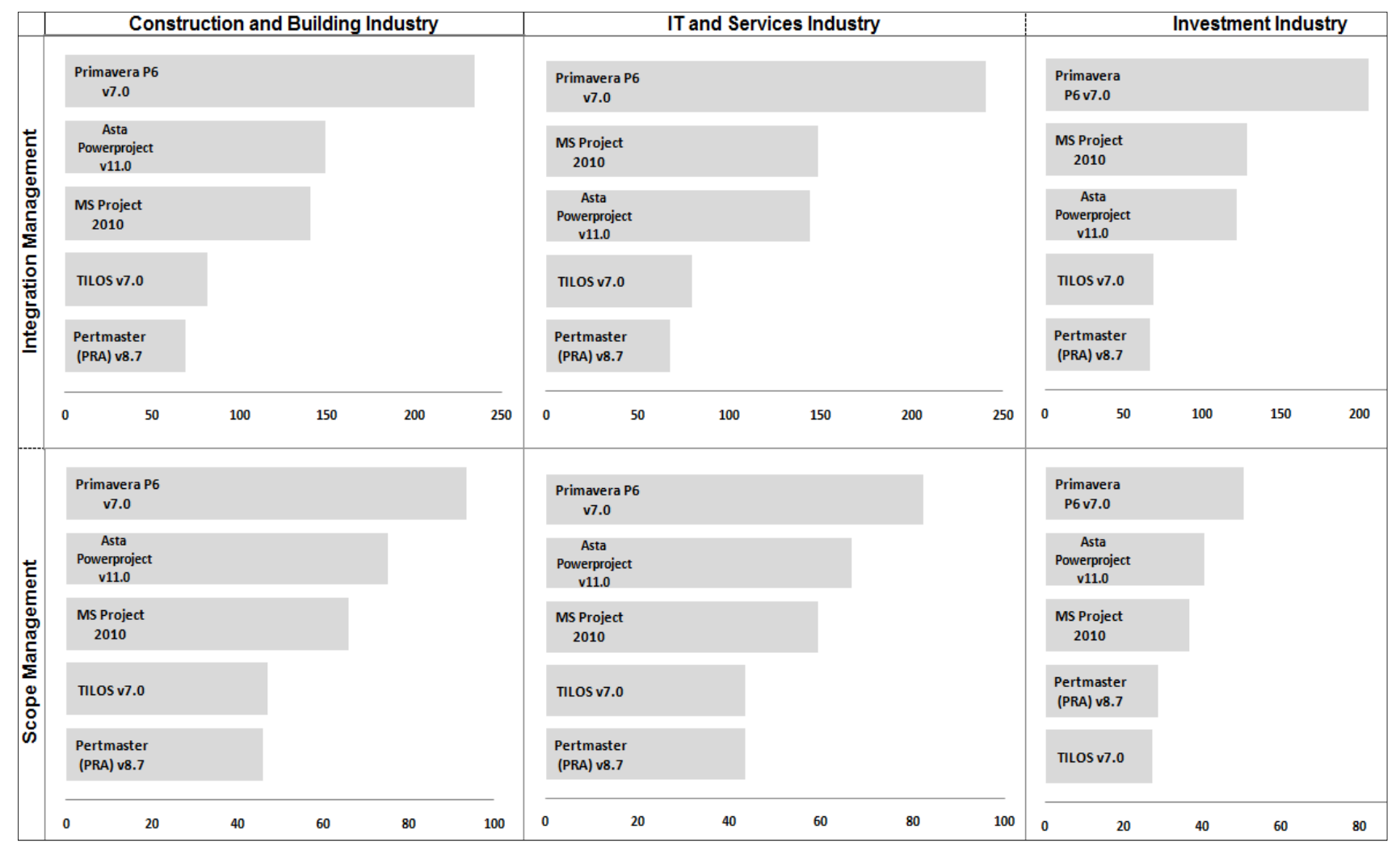

Figure 2. Summary of scores achieved by the tested systems in the area of integration and scope management (source: own research)

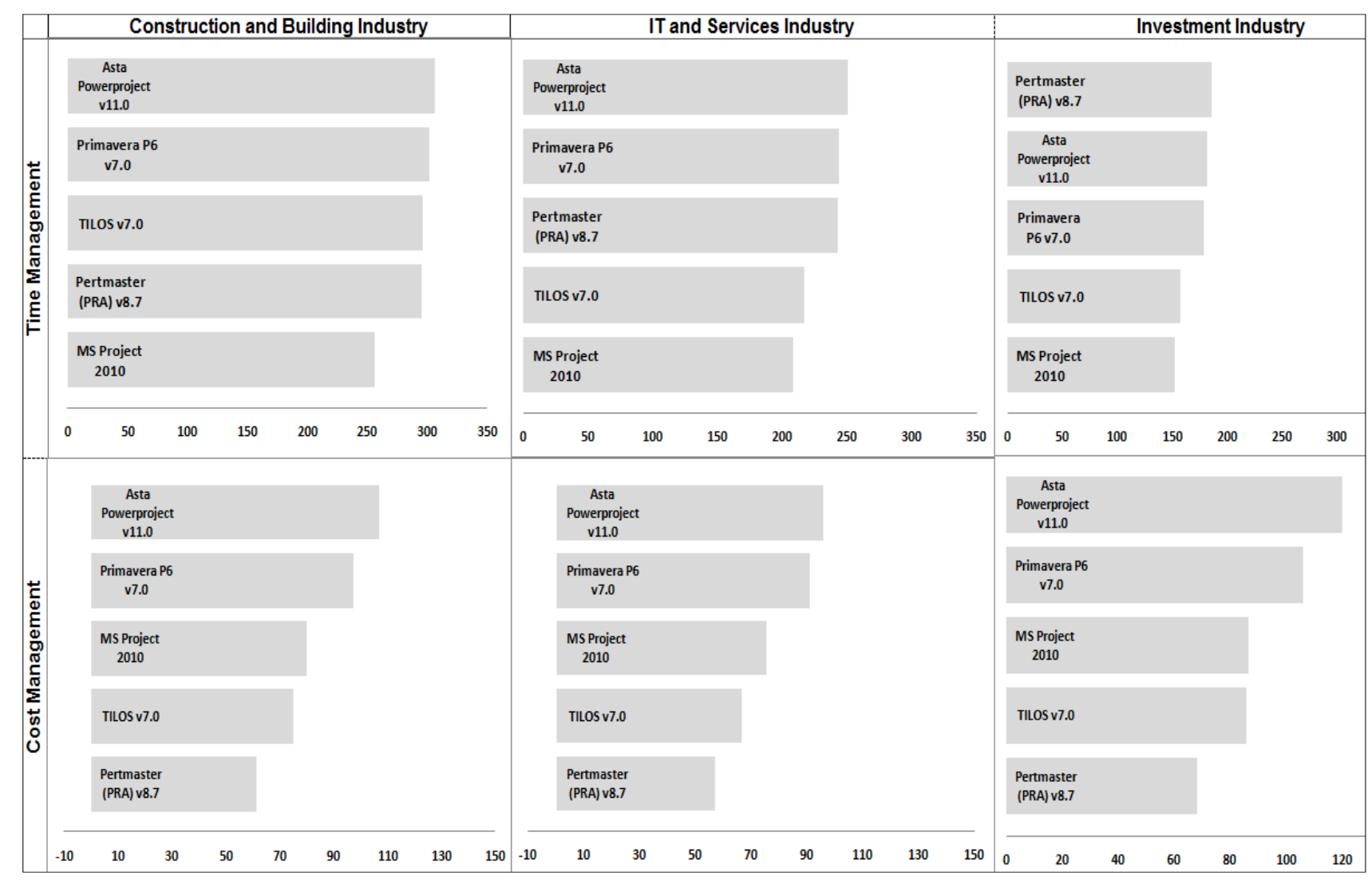

Figure 3. Summary of scores achieved by the tested systems in the area of time and cost management (source: own research) 


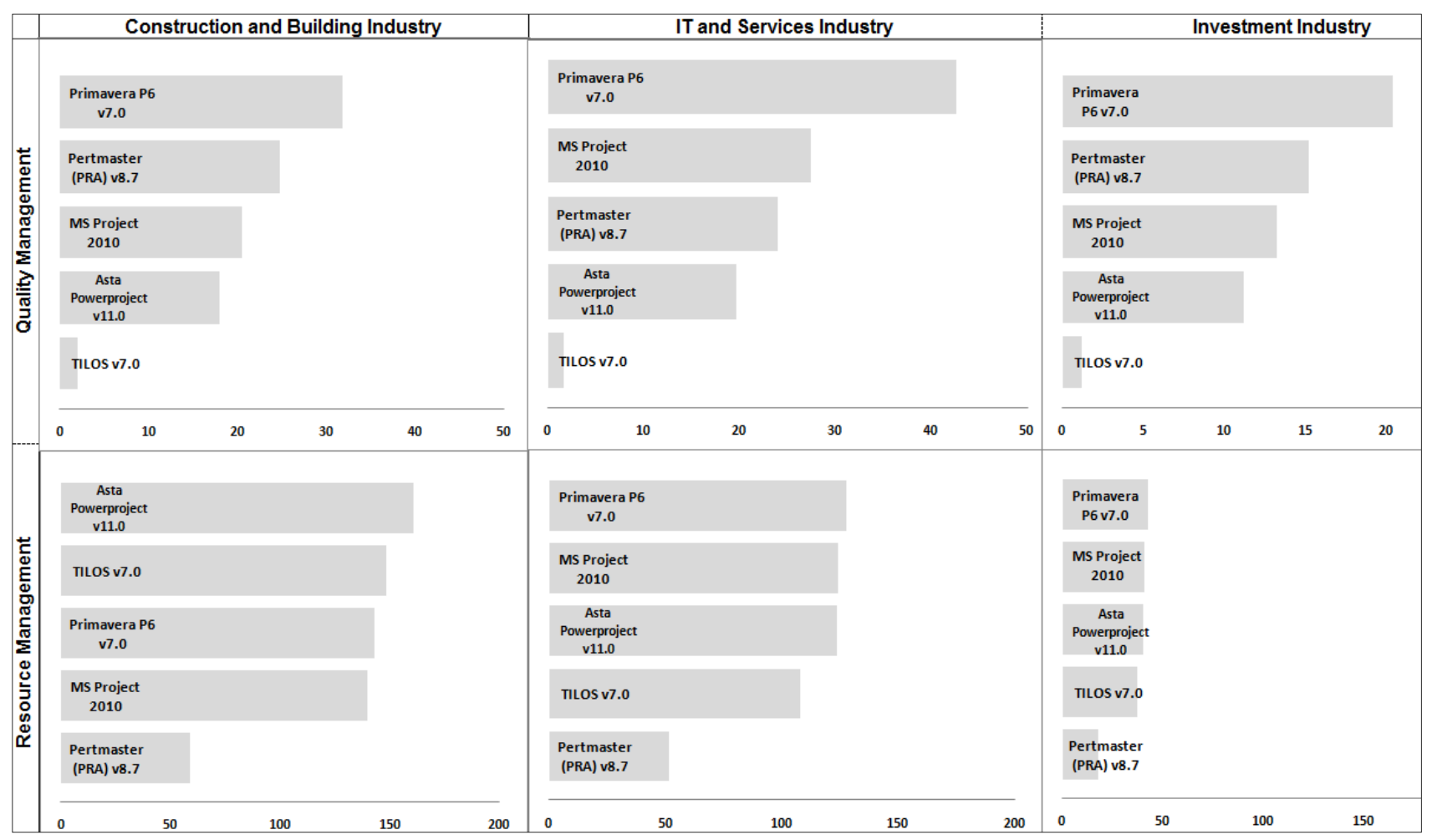

Figure 4. Summary of scores achieved by the tested systems in the area of quality and resource management (source: own research)

Asta Powerproject wins second place in the construction and building industry due to advanced functionalities in the area of project management plan development and project management, well suited to this industry.

Within the scope management P6's advantage is no longer so clear, and was achieved by best-in-class mechanism for creating a work division structure relatively easy to use and clearest.

Fig. 3 shows high scores obtained by all systems in the area of time management, which is not surprising as that is an area used independently of other factors by all users.

Asta Powerproject wins by advanced functions of building and presentation of the schedule, which are often innovative in relation to the competition.

It only gives ground to Pertmaster (PRA), which gains an advantage in areas where advanced feature of schedule building are not absolutely necessary, that is in the investment industry. Pertmaster's strengths (PRA) are primarily the possibility of advanced estimation of the duration and building a probabilistic schedule and the possibility of its analysis with a Gantt diagram, which gives a good visualization of uncertainty and risk events as well as by using statistical graphs.
Primavera P6 presents a solid functional range, and TILOS dedicated only to the building and construction industry shows its advantages by taking third place.

Asta Powerproject is a leader in the area of cost management, its functionalities allow for the most detailed description of the nature of the project expenditure. Asta also allows to record revenues. Primavera P6 makes up for its deficiencies with best practices in the field of earned value management and a clear presentation of data.

Fig. 4 shows the advantage of Primavera P6 in the area of quality management, because it can summarize data at the level of a project by a number of graphs that can be used to make a technical measurement of the project.

In this respect also Pertmaster (PRA) and MS Project do well, the latter especially well in the IT industry thanks to a good service of iterative works (review). There is a clear division into industries within the resource management, where Asta and TILOS do well in managing equipment and materials by providing a base of standards and mechanisms calculating quantity surveys. 


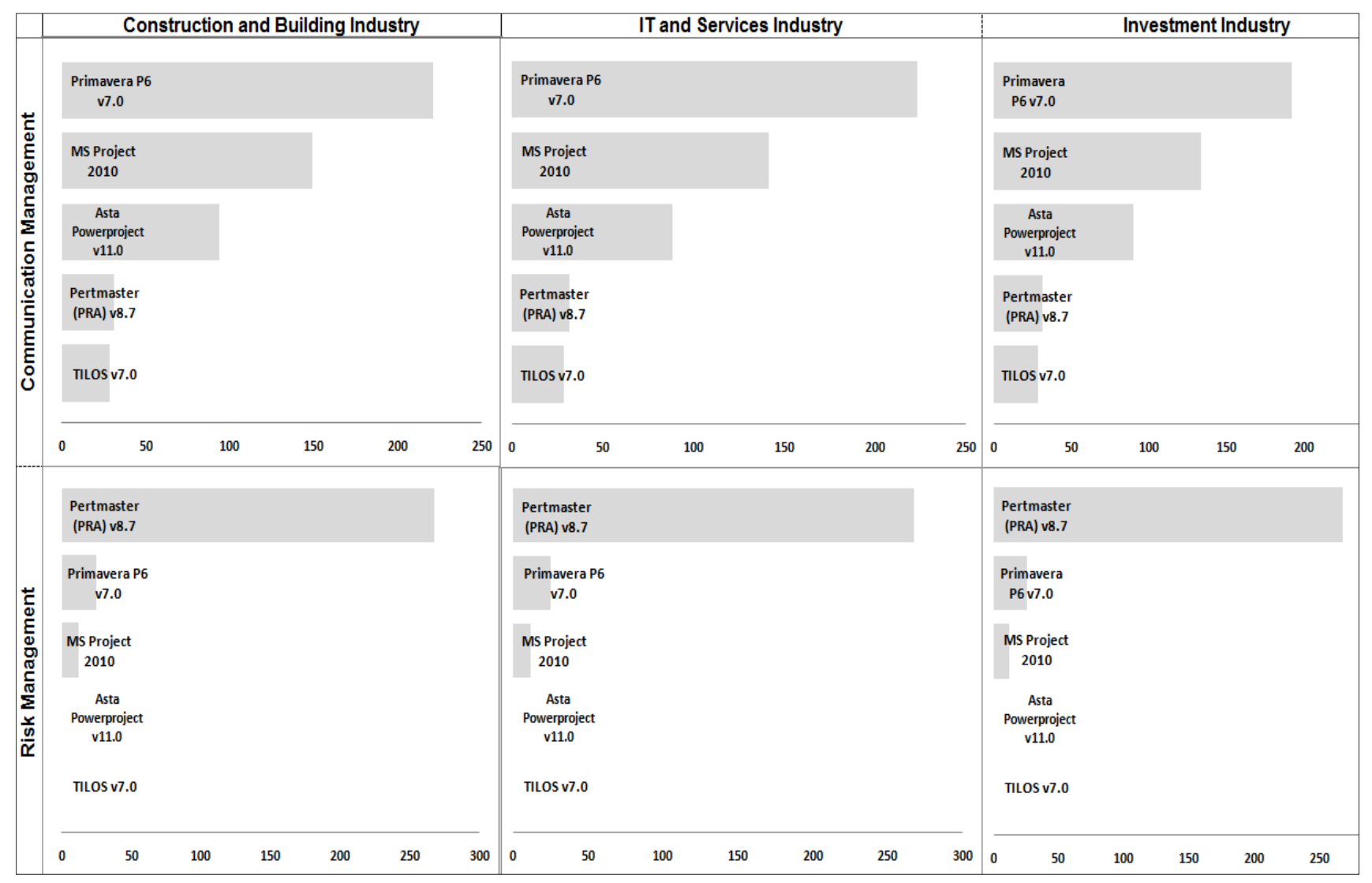

Figure 5. Summary of scores achieved by the tested systems in the area of communication and risk management

(source: own research)

Primavera P6 and MS Project gain a minimum advantage through long-term resources planning in other industries.

Communication management (see Fig. 5) is largely dominated by Primavera P6 due to the highly advanced reporting capabilities, document management, and the function of determining and reading the project's organizational structure, available also at the level of work breakdown structure.

In the area of risk management Pertmaster (PRA) is second to none, both due to a highly advanced risk management module, but also due to the incompetency of competitors in this field.

Traces of risk management can be found in Primavera P6, while the points awarded to MS Project are the result of the presence of a registry, which, however, has no effect on the project plan.

An attempt was made to choose the best solution for each of the industries, however, this result should be treated as pictorial rather than as a real indication in selecting a PMIS.
This is due to several factors:

- the result is the sum of solutions in all areas, while very rarely end-users use all, and certainly not all of them in the same way,

- some systems are dedicated to a narrow range of use in projects, but due to the specialization in these narrow applications they are next to none. An example would TILOS be for individual linear projects, or Pertmaster (PRA) for risk management,

- the score was awarded taking into account the wealth of multiple projects management in a central database and options for restricting users' access to parts of projects and editing options, therefor systems like TILOS or Pertmaster (PRA), by definiton, scored lower in certain requirements. It should be noted, however, that often companies use joint solutions such as EPPM combined with RPM or LPM systems.

Summing up the results of comparison in Fig. 6 and Fig. 7, one can see that the most versatile of the tested systems is Primavera P6, the least TILOS. 


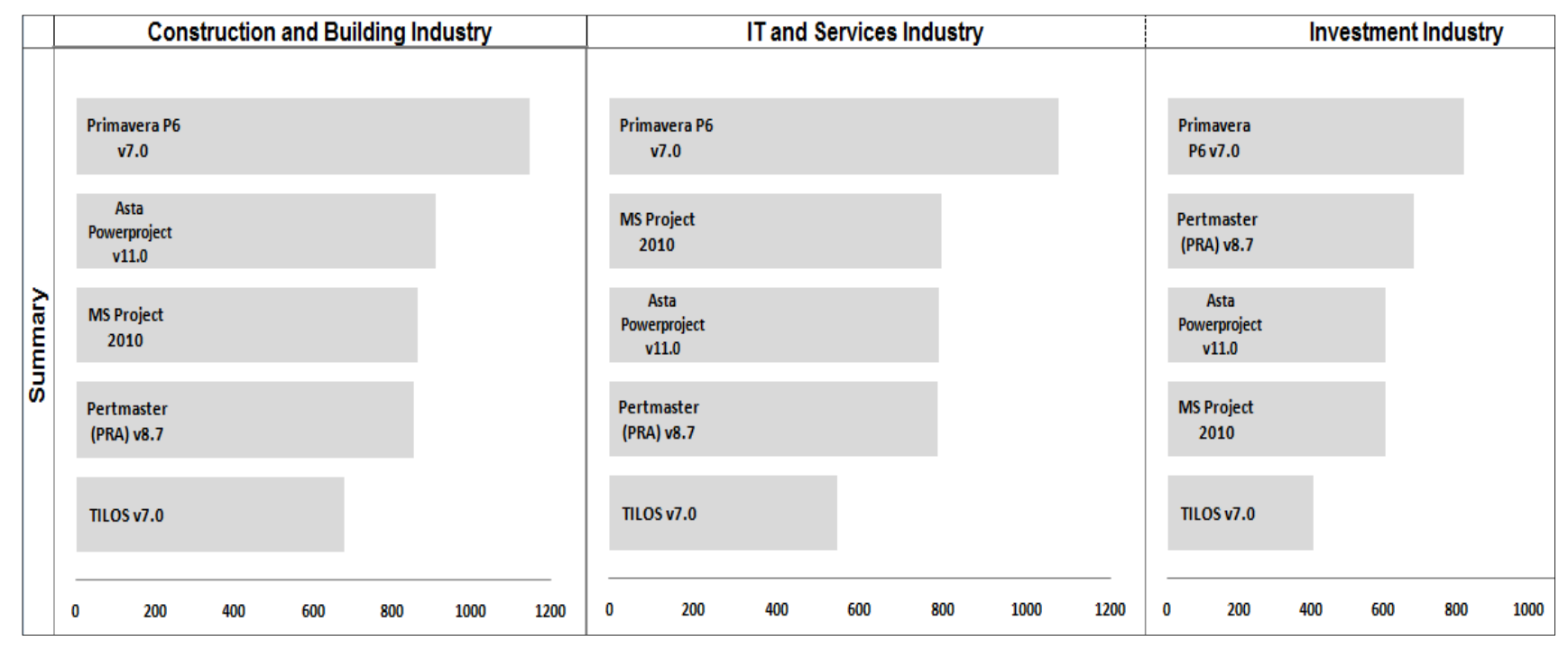

Figure 6 . The combined results achieved by each of the systems in respective industries (source: own research)

Asta Powerproject is strong in construction and building industry, and in fact its dedicated functionalities for this sector often, more than any others, determine the choice by the users.

MS Project, which is the most popular choice because of its price and distribution system, is created by the manufacturer with the IT and services industry in mind, excluding many important solutions for other industries.

Compared with Primavera P6 it is still in its infancy as a network solution and much more impressive is the version of MS Project 2010 Professional (than MSP 2010 Server), which introduced a few interesting innovations to the market, particularly in the management of human resources.

Pertmaster (PRA) wins where the main focus is on the risks and taking into account the pie chart showing the share of functional solutions in breakdown into areas of management, this should not be a surprise. The following chart of Pertmaster (PRA) as well as other tested systems, shows the share of functional solutions in a given area in relation to all that have been presented for a given system in this study. This means that one cannot compare these graphs with each other, only the areas within a single system.

\section{Summary}

Described above comparison of systems is one of the products of the study. It was assumed, that it is impossible to propose improvements in project management using information systems, without a detailed diagnosis of their abilities. The second product of the study is a list of those among relevant functional solutions that are found only in some systems, and may be important to strengthen the position of the manufacturer on the market in the event of implementation of their system. These solutions were rated 9 or 10 , while other systems for the same solution received 0 rating.

Third important product of the study are offered innovative functionalities that provide the answer to some of the requirements from users of PMIS. Their innovation lies in the fact that none of the tested systems features them, and they can provide significant advantages in project management. How can this be measured? A similar method was used as in the comparison of existing solutions. Details are presented below:

- an assessment of the impact of innovation on each of the areas of management,

- within the area of management the results were divided into industries,

- results were illustrated by graphs showing the percentage of the weight of innovation in relation to the weight of the existing functionalities described in the study,

- weights are derived from the main table called Comparison of solutions in which every solution received weight for individual industries, which was multiplied by $\%$ share in process implementation. 

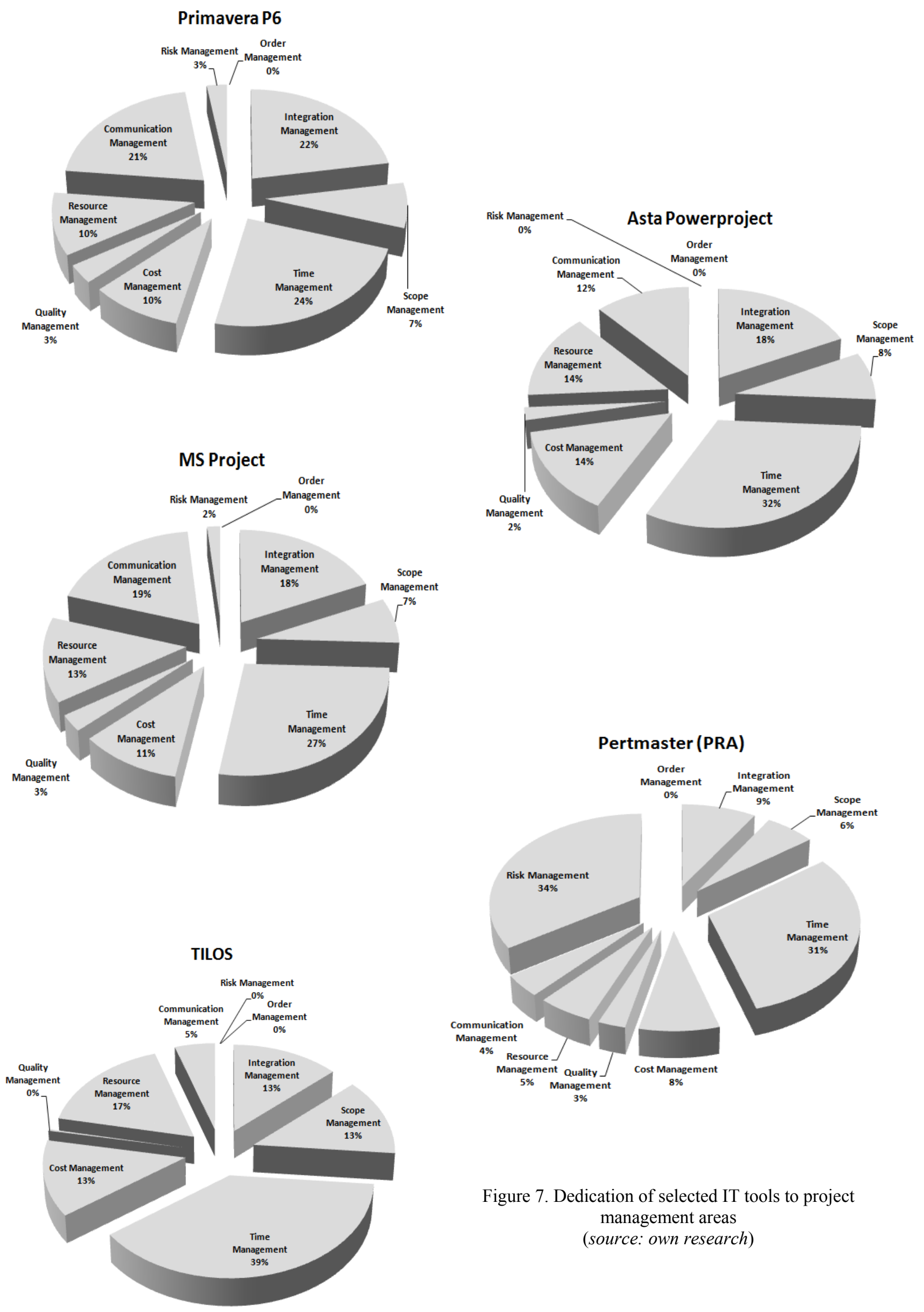

Figure 7. Dedication of selected IT tools to project management areas (source: own research) 


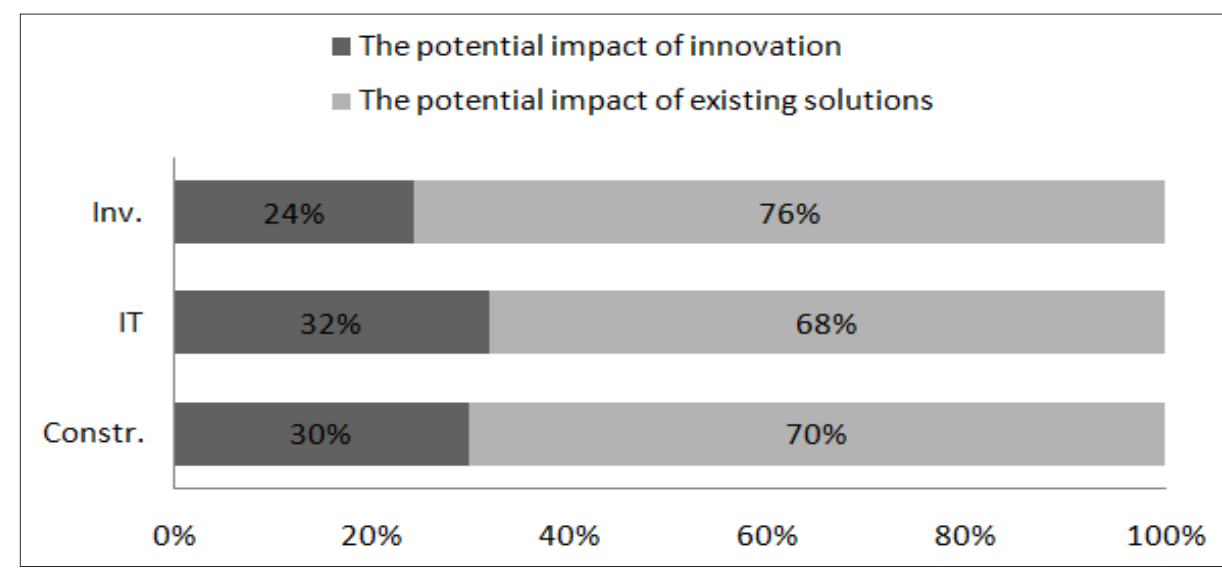

Figure 8. Combined summary of the potential impact of new solutions on industries (source: own research)

As a result of employing this methodology, results were obtained for the various areas of management.High development of selected areas of project management in PMIS, such as time management in all the tested ones, or the risk management in Pertmaster (PRA), result in the fact that the proposed innovative functionalities do not have a decisive shape over the system capabilities in a given area of the project. The opposite of this situation is the area of order management, for which it was concluded, that there is lack of dedicated functions (although there are support functions) among the tested systems. Therefore, suggesting a fairly complex function in such a significant way affects individual industries.

It is worth noting that most of the areas achieve significant potential functional growth compared to the original. A smaller impact is noted by already highly functionally developed areas of management in at least one of the tested PMIS, such as:

- time management,

- resource management,

- risk management.

Final average results of the impact of innovation are at a level just under 30\% which (see Fig. 8), taking into account the functional complexity of existing solutions, should be considered a satisfactory result. This result should all the more be of interest to software vendors when all these functional solutions are added, which a system of a given vendor does not have, but are present in a competitor, and match the profile of the target group of clients.
The results of this study should provide value for:

- system users, since it fits their industries and management areas most important for them,

- software vendors, as they will be able to review the strengths of competition,

- software vendors as they will be able to review user requirements in terms of solutions missing on the market (or at least on a large part of the market),

- consultants and others parties interested in standardizing project management employing IT solutions,

- methodology developers who have a chance to see that resource management does not apply to human resources in projects only, and that projects worth paying attention to are linear projects, because for both management techniques require advanced planning.

The presented study may constitute a starting point for an in-depth analysis within the "Compendium of good practice for implementation of PIMS".

This analysis would include practical examples of implementations and application of different tactics depending on the size, industry and involvement of organizations in implementation. An example of such tactics might be purposeful coupling of work cards functionality in PMIS in the IT and services industry with a financial module of ERP system, settling reported work hours. Such an integration may be crucial for the motivation of project managers and teams implementing projects to implement a project management methodology by an IT system standardizing the work. 
Another element that could enrich the study work would be a chapter dedicated to the functional requirements and solutions supporting project management called "Requirements across management processes", which could include functionalities aimed at:

- managing multiple projects (IT functions and functions corresponding to requirements defined in the theory of portfolio management by Henry Markowitz),

- administering global system data (authority, global data structures),

- adapting functions of data availability (limited view of unnecessary functionalities for users with limited privileges),

- tracking user activity,

- functions of integration with other applications (export/import, API, SDK, Web Services),

- functions of action adaptation (internal functions, Excel Asta and Pertmaster (PRA) macros).

Based on research of these topics it could probably be possible reach further conclusions regarding functional solutions on the borderline of IT and management, whose implementation would be a real support for the business. This follows from the fact that it is impossible, in any organization implementing a PMIS, to avoid the following topics:

- limiting complexity of the system for certain users,

- integration with other business applications,

- possibility of easy functionality increase through VBA, and user activity tracking, building accountability for actions within IT systems.

\section{References}

[1] Apgar D. - Inteligencja ryzyka. Jak nauczać zarzqdzania niewiadomym? Helion, Gliwice 2008.

[2] Goldratt E.M. - Łańcuch Krytyczny, Werbel, Warszawa 2000.

[3] Harvard Business Essentials - Zarzqdzanie projektami matymi $i$ dużymi. MT Biznes, Warszawa 2006.

[4] Kosieradzka A. - Metody Organizacji i Zarzqdzania. Politechnika Warszawska, Warszawa 2010.

[5] Koszlajda A. - Zarzqdzanie projektami IT. Przewodnik po metodykach. Helion, Gliwice 2010.

[6] Patterson D. - Taming an Unruly Schedule Using a 14 Point Schedule Assessment, Acumen - Project Confidence, 2010.

[7] Pazio W.J. - Zarzqdzanie finansami. Repetytorium. Oficyna Wydawnicza Politechniki Warszawskiej, Warszawa 2006.

[8] Primavera - Pertmaster Course 501 - version 8.2. Bala Cynwyd, Primavera Systems Inc., 2008.

[9] Pritchard C.L. - Zarzqdzanie ryzykiem w projektach, Teoria i praktyka. WIG - PRESS, Warszawa 2002.

[10] Project Management Institute - Project Management Body Of Knowledge Guide - Fourth Edition. Management Training \& Development Center, Warszawa 2009.

[11] Webb A. - Wartość wypracowana w praktyce. PROED, Warszawa 2008.

[12] Wysocki R.K., McGary R. - Efektywne Zarzqdzanie Projektami. Wydanie III, Helion, Gliwice 2005. 